\title{
APRENDIZAGEM CENTRADA NA PESSOA: A ATUALIDADE DA PROPOSTA EDUCACIONAL DE CARL ROGERS
}

\author{
PERSONAL-CENTRALIZED LEARNING: THE CURRENCY \\ OF CARL ROGERS'S EDUCATIONAL PROPOSAL
}

\author{
APRENDIZAJE CENTRADO EN LA PERSONA: LA ACTUALIDAD \\ DE LA PROPOSTA EDUCACIONAL DE CARL ROGERS
}

Clóvis Martins Costa

RENATA SiEIRo FERNANDES ${ }^{2}$

'Centro Universitário de Jaguariúna (UniFAJ), Jaguariúna-SP, Brasil ${ }^{2}$ Centro Universitário Salesiano de São Paulo (UNISAL), Americana-SP, Brasil

Resumo O objetivo deste artigo é apresentar e analisar os conceitos e o pensamento de Rogers de modo a trazer as contribuições dele no campo da Educação para o contexto atual, especialmente o de aprendizagem significativa. Isto implica mudar o foco do ensino para aprendizagem e do professor ou da professora para o do aluno e da aluna. A pesquisa é qualitativa, de campo teórico, do tipo bibliográfica e documental. É feita uma revisão de teses, dissertações e artigos sobre o assunto e são buscadas cinco experiências atuais de docentes que conversam com o pensamento rogeriano. O referencial teórico é a obra de Carl Rogers, aplicada à educação e à abordagem centrada na pessoa. Os dados encontrados indicam resultados positivos no sentido da validade e da atualidade da proposta humanista e humanizadora, assumindo-se a dimensão humana, cultural, social e comunitária da educação. E confirmam os dados encontrados por Rogers e seus colaboradores e as experiências atuais se mostram possíveis de serem feitas mesmo em ambientes educacionais mais conservadores e tradicionais. A atualidade do pensamento rogeriano se constitui numa possibilidade de educação para a consciência crítica, para a autonomia e para a emancipação, valores tão ausentes no (des)atual modelo de educação tradicional vigente, de elevado conservadorismo, reprodutivista, conteudista nos diferentes níveis de escolarização.

Palavras-chave: Educação; Carl Rogers; Aprendizagem centrada no aluno.

ABSTRaCT The purpose of this article is to present and analyze Roger's concepts and thinking in order to bring his contributions in the field of Education to the current context, especially

Comunicações Piracicaba |v. $27 \mid$ n. 2 | p. $21-40 \mid$ maio-ago. 2020 DOI: http://dx.doi.org/10.15600/2238-121X/comunicacoes.v27n2p21-40 
that of meaningful learning. This implies moving from the focus of teaching to that of learning and the center in the teacher to the student. The research is qualitative, of theoretical field, of the bibliographical and documentary type. A review of theses, dissertations and articles on the subject is made and five experiences of teachers who speak with Rogerian thinking are sought. The theoretical reference is the work of Carl Rogers, applied to education and the person-centered approach. The data found indicate positive results in the sense of the validity and timeliness of the humanistic and humanizing proposal, assuming the human, cultural, social and communitarian dimension of education. And they confirm those found by Rogers and his family and current experiences prove to be possible even in more conservative and traditional educational settings. The present relevance of Rogerian thought constitutes a possibility of education for the critical conscience, for autonomy and for emancipation, values that are so absent in the (current) current model of traditional education, of high conservatism, reproductive, content in different levels of schooling.

Keywords: EduCATIOn; CARL Rogers; Student-CENTERED LEARNing.

RESUMEN El objetivo de este artículo es presentar y analizar los conceptos y el pensamiento de Rogers, de modo a traer sus contribuciones en el campo de la Educación al contexto actual, especialmente el de aprendizaje significativo. Esto implica pasar del foco de la enseñanza al del aprendizaje y del centro en el / la profesora / a para el / la alumno / a. La investigación es cualitativa, de campo teórico, del tipo bibliográfica y documental. Se hace una revisión de tesis, disertaciones y artículos sobre el asunto y se buscan cinco experiencias de docentes que conversan con el pensamiento rogeriano. El referencial teórico es la obra de Carl Rogers, aplicada a la educación y el enfoque centrado en la persona. Los datos encontrados indican resultados positivos en el sentido de la validez y la actualidad de la propuesta humanista y humanizadora, asumiendo la dimensión humana, cultural, social y comunitaria de la educación. Y confirman los que fueron encontrados por Rogers y sus y las experiencias actuales se muestran posibles de ser hechas, incluso en ambientes educativos más conservadores y tradicionales. La actualidad del pensamiento rogeriano se constituye en una posibilidad de educación para la conciencia crítica, para la autonomía y para la emancipación, valores tan ausentes en el actual modelo de educación tradicional vigente, de elevado conservadurismo, reprodutivista, conteudista en los diferentes niveles de escolarización.

Palabras Clave: Educación; Carl Rogers; Aprendizaje Centrado en el alumno.

\section{INTRODUÇÃo}

Não podemos ensinar alguém diretamente; só podemos facilitar seu aprendizado.

Carl Rogers

O problema que instiga a pesquisa é a pertinência e a atualidade do pensamento de Carl Rogers na Educação, ou não. Dessa forma, o objetivo é apresentar e analisar os conceitos e o pensamento de Rogers de modo a trazer as suas contribuições no campo da Educação para o contexto atual. 
Rogers, a partir de suas obras, elege pontos que considera importantes e fundamentais de sua vida, influenciando sua prática e suas reflexões teóricas, vindo a compor o corpo de seu referencial teórico tanto para a área da psicoterapia como da educação.

A fim de conhecer o campo da pesquisa em Educação sob a perspectiva de Rogers, em que esses conceitos e outros podem estar presentes, mas especialmente o da aprendizagem centrada no aluno e na aluna, foram buscados teses, dissertações e artigos relacionados ao assunto e disponíveis em bases acadêmicas.

Conclui-se, a partir do levantamento inicial, que Rogers e Educação não têm sido temas associados presentes nas pesquisas, sendo mais comum na área da Saúde e da Psicologia. Esse aspecto aponta para uma lacuna que merece ser preenchida com, inclusive, esta pesquisa de Mestrado, e outras que possam vir a agregar conhecimento para a área da Educação, valendo-se de tal referencial de ancoragem.

No livro "Liberdade para Aprender" (1978), Rogers reúne seus artigos, suas pesquisas e suas ideias sobre Educação. Anuncia no prólogo do livro o assunto que pretende nele tratar: aprendizagem. E anuncia, também, o tipo de aprendizagem que pretende abordar. Refere-se à aprendizagem entendida como uma insaciável curiosidade que leva a querer saber tudo que diz sentido à vida de quem está aprendendo.

O autor considera que, de modo geral, há duas espécies de aprendizagem. Uma delas é a que ele chama "do pescoço para cima", que lida apenas com o cérebro e não tem relevância para a pessoa como um todo. É aquela que inicia o processo por apresentar às crianças letras e sílabas sem qualquer sentido para elas e progressivamente vai criando e oferecendo currículos que em muito não dizem respeito a elas nem aos seus interesses em saber. Nela se aprende com grande dificuldade e logo se pode esquecer.

Em oposição a essa espécie há outra, que é plena de sentido, denominada de "experiencial" ou "significativa". Ele busca definir os elementos envolvidos nessa aprendizagem significativa ou experiencial: envolve a pessoa como um todo, tanto sob o aspecto sensível quanto sob o cognitivo; é autoiniciada e mesmo que o primeiro impulso seja externo à descoberta, o alcançar, o compreender vem de dentro; é penetrante e suscita mudanças no comportamento, nas atitudes e mesmo na personalidade do aprendiz ou da aprendiz; é avaliada pelo educando ou pela educanda, pois ele(a) é quem sabe se está indo no caminho do que deseja saber, do que necessita aprender em atenção à sua ignorância; o significado é a sua essência e se dá na sua experiência como um todo.

Na primeira, o centro do processo está no professor ou na professora, que tem como objetivo "ensinar" e na segunda o centro do processo está no aluno e na aluna e o professor ou a professora são os facilitadores do "aprender".

No campo da Educação, os conceitos de ensino e de aprendizagem centrados no aluno e na aluna são fundamentais de serem melhor entendidos e abordados, tanto teórica quanto metodologicamente.

\section{DesenVOLVimento}

Rogers já havia posto as bases da Abordagem Centrada na Pessoa no livro "Psicoterapia e Consulta Psicológica" (1987 [1942]), tendo promovido com isso uma mudança 
de rumo revolucionária no campo da psicoterapia. Na sua proposta de terapia centrada no cliente, o autor vê uma significativa diferença no processo em relação às demais abordagens, considerando-o como uma "aprendizagem" que a pessoa vai desenvolvendo em relação a si mesma e ao seu mundo e, assim, ganhando uma autonomia em relação à sua vida e aos problemas que enfrenta, bem como, aos que vier a enfrentar.

Ao escrever o livro "Terapia Centrada no Cliente" (1992 [1951]), Rogers apresenta uma teoria da terapia e uma teoria da personalidade. Na busca por explicar o processo terapêutico e a estrutura básica da personalidade, o livro apresenta o perfil dos profissionais e das profissionais que trabalham nessa perspectiva humanista complementado pelos depoimentos gravados de pessoas que experimentaram essa forma de terapia.

Nesse livro, o autor diz que considera natural que alguém conhecendo os resultados da Abordagem Centrada na Pessoa - (ACP) no processo terapêutico se pergunte por que isso não ocorreria em outras áreas de atividade. Ele afirma:

\begin{abstract}
Se, na terapia, é possível basear-se na capacidade do cliente para lidar construtivamente com sua situação de vida, e se a meta do terapeuta é melhor dirigida quando se volta para a liberação dessa capacidade, então por que não aplicar essa hipótese e esse método de ensino? Se a criação de uma atmosfera de aceitação, compreensão e respeito é a base mais eficaz para facilitar o aprendizado que se chama terapia, não poderia ser também a base para o aprendizado que se chama educação? (ROGERS, 1992, p. 439).
\end{abstract}

A partir desses questionamentos, vários profissionais que conheciam a ACP começaram a fazer adaptações em sala de aula. Entre experiências malsucedidas e algumas com relativo sucesso o que se mostrou é que se estava propondo um jeito revolucionário de dar aula, no sentido da originalidade, da inovação, da possibilidade de renovar os padrões até então estabelecidos.

Rogers diz que a descoberta e implementação das implicações da terapia centrada no cliente para a educação foram impulsionadas pelas suas próprias experiências em sala de aula, bem como, de pessoas a ele ligadas, mas que a contribuição desses outros autores e dessas outras autoras foi muito importante e enriquecedora. Ele reconhece que suas experiências radicais em educação têm inspiração em princípios de John Dewey, William Kilpatrick e outros e outras, bem como, acredita que muitos outros professores e muitas outras professoras, competentes, insatisfeitos e insatisfeitas com os métodos tradicionais possam ter chegado a resultados semelhantes.

Os princípios de democracia e liberdade na Educação, oriundos de Dewey, chegaram até Rogers por meio das aulas tidas com Kilpatrick. Desses princípios, entusiasmaram-no os elementos pedagógicos voltados para a liberdade de pensar do aluno e da aluna, bem como, o estímulo à sua participação na aula. Tais elementos eram contraditórios com as práticas e metodologias comumentemente presentes no espaço escolar, ancoradas numa abordagem tradicional de ensino.

Os conhecimentos do aluno e da aluna deveriam ser valorizados e problematizados, o que representava um foco no aluno e na aluna como sujeito do processo de aprendizagem.

Rogers esclarece que a meta de um ensino centrado no aluno e na aluna é a de contribuir com a formação de sujeitos críticos, capazes de fazer escolhas, de iniciativas pró- 
prias, de reconhecer a contribuição dos outros, bem como, da solidariedade, de adquirir conhecimentos e deles se servir para a solução de problemas, enfim de uma formação no sentido da autonomia. É uma tentativa de encontrar um método que possa atingir uma meta democrática.

Costa (1980) enaltece a contribuição de Rogers dentro da pedagogia libertária exaltando a liberdade de aprender, o resgate do poder pessoal do aluno e da aluna frente ao autoritarismo da educação tradicional. O autor, como Rogers, é utópico, no sentido do lugar que ainda não existe, com esperança nessa proposta educacional que criaria uma nova sociedade mais livre e mais humana.

Em educação o que se pretende é crescimento, o que vai significar mudança no self $f^{1}$ e isso poderá representar ameaças ao self, o que dificulta o aprendizado significativo. As hipóteses e princípios referidos são decorrentes de experiências e não apenas pressupostos. Inicialmente, partiu-se da técnica do professor e da professora. Na medida em que as atitudes do professor e da professora foram sendo capazes de criar um clima de aceitação na sala de aula, as técnicas específicas ocuparam um plano secundário. Eiserer (1949), sobre essa relação, diz que se o professor e a professora aceitam os alunos e as alunas como são, permitem que expressem os seus sentimentos com liberdade e planejam atividades de aprendizagem com e não para eles (para elas), o clima da sala de aula será diferente, livre de tensões e pressões emocionais e os resultados numa direção de objetivos democráticos.

Os objetivos dos alunos e das alunas devem estar em primeiro lugar. Rogers sugere que o professor ou a professora comece por perguntar aos alunos e às alunas quais são os objetivos de cada um para aquela disciplina ou para aquele curso. Aos poucos vão surgindo as questões e as necessidades e o currículo daquela classe vai sendo construído.

As ideias de Rogers estão mais próximas de concepções mais dinâmicas de currículo, como a de Silva (2011) em que currículo é tudo que se ensina e se aprende dentro e fora da sala de aula, dentro e fora dos conteúdos das disciplinas.

O currículo é onde se incluem ou se excluem determinados saberes sob determinadas formas de socialização, em torno de diferentes significados sobre o social, o cultural, o histórico, o político. Para Silva (2010), é pelo currículo que se produzem práticas de significação pela atividade linguística, práticas produtivas, relações sociais e de poder e identidades sociais (p. 17).

Por meio dele os sentidos são construídos, desconstruídos, contestados, negociados, transformados (SILVA, 2010, p. 25). Sendo assim, é lugar de poder, de saber e que produz identidades na medida em que:

(...) O currículo é lugar, espaço, território. O currículo é relação de poder. $\mathrm{O}$ currículo é trajetória, viagem, percurso. O currículo é autobiografia, curriculum vitae: no currículo se forja nossa identidade. O currículo é texto, discurso, documento. O currículo é documento de identidade (SILVA, 2011, p. 150).

Para o autor, o currículo nos produz. Alinhados os pensamentos de Rogers e de Silva, o currículo pode ser um parâmetro e uma referência para a avaliação dos conteúdos nele

Para Carl Rogers Self é Autoconceito e noção de eu, é a percepção de si e da realidade pela própria pessoa. 
propostos com a participação ativa dos alunos e das alunas, a serem considerados e consideradas em suas opiniões, percepções e sugestões com possibilidades de modificações, exclusões ou inserções nos conteúdos ali contidos.

Esse novo jeito de aprender, proposto por Rogers, não se dá sem problemas, pois muitos alunos e muitas alunas ao entrarem em contato com um novo modo educativo, podem ter reações negativas à novidade, chegando a questionarem a sua validade e a solicitar que se retome o modo anterior centrado no professor ou na professora.

Rogers relata que nos primeiros cursos centrados no aluno e na aluna o aspecto que mais se destacava nas avaliações de final de curso era a atmosfera geral da classe e seus efeitos positivos, nela e fora dela, na vida cotidiana dos participantes e das participantes. Tais efeitos eram a liberdade, a autonomia, a autocrítica, a autoconfiança, a aprendizagem significativa processual e contínua. Ele cita pesquisadores e pesquisadoras que corroboram essa informação, como Anderson, Brewer (1945) e Withall (1948).

Um curso centrado nos alunos e nas alunas começa e deve continuar em torno dos objetivos destes e destas. Outro ponto importante é que o professor ou a professora deve apresentar aos alunos e às alunas uma gama de materiais e recursos, como: discussão em sala de aula, aula expositiva, leitura de artigos relacionados ao tema, documentários, visitas a ambientes e outros, que possam facilitar o processo e contribuir para atingir as metas por eles propostas. $\mathrm{E}$ isso deve se dar de forma atualizada, sempre, no início e no decorrer do curso, considerando que os objetivos podem igualmente se atualizar e se ampliar.

A diversidade de recursos apresentada favorecerá a liberdade de escolha dos alunos e das alunas, não impondo a eles e a elas a obrigatoriedade de adesão a este ou aquele recurso específico.

É importante que o professor ou a professora confie no grupo e permita que os alunos e as alunas assumam a responsabilidade pelo curso. Se aquele ou aquela começa a dar respostas definitivas às questões trazidas, retorna-se ao processo centrado nele ou nela e os alunos e as alunas vão se tornando novamente dependentes e com menos autonomia.

Rogers aborda, também, a questão da avaliação quando esse tipo de abordagem é praticado em sala de aula. E para ele a única resposta condizente a essa questão é a autoavaliação, bem preparada e bem-feita, pois só o próprio aluno ou a própria aluna, responsável, pode dizer se a sua meta foi atingida ou não, e em que grau, e ainda outros aspectos como se a experiência foi significativa ou se fracassou. A autoavaliação não é um processo fácil, mas vai sendo construída a partir da consciência de que o aluno ou a aluna é o centro da aprendizagem e, por conseguinte, o centro da avaliação, também. A autoavaliação é também aprendizagem e crescimento no mesmo processo de educação. Essa avaliação, porque é fundamentada na confiança, se contrapõe ao processo avaliativo praticado pelo sistema tradicional que avalia o aluno e a aluna a partir da perspectiva do professor ou da professora.

Ele cita algumas das muitas formas conciliatórias, como: a participação dos alunos e das alunas na elaboração de questões para o exame; a autoavaliação individual escrita; a autoavaliação oral com discussão dos demais colegas e das demais colegas e professor ou professora para a validação, quando em grupo pequeno; a autoavaliação com conceito de aprovado e aprovada ou reprovado e reprovada, quando aceito pela instituição; a autoavaliação escrita com justificativa e combinados para que essa nota fosse entregue pelo 
professor ou professora, exceto se ele ou ela não concordasse e, então, chamaria o aluno ou a aluna para uma conversa e juntos ou juntas chegariam à nota.

O método propicia a consciência de que a nota atribuída por uma avaliação externa é altamente artificial e pouco significativa. E essa avaliação tradicional, na experiência do autor, se mostrou como obstáculo ao crescimento do aluno e da aluna, não contribuindo para o desenvolvimento de seu self mais maduro, responsável e socializado. Ao contrário, quando o lócus da avaliação é interno, o crescimento pessoal é incentivado.

$\mathrm{O}$ incômodo com a dificuldade de aprender no sistema tradicional e a busca constante de outros jeitos de promover a aprendizagem, para Carl Rogers, vão além da aprendizagem em si. Ele vê na Educação, como em outras relações humanas, uma expressão de vida mais plena ou menos plena. Ele busca aí mais um sentido em aprender aquilo que é significativo, que faz sentido para a vida de cada um, ou de cada uma, que contribua para a realização da pessoa em termos de uma vida mais plena. E esse processo é fundamental para a realização de uma sociedade de pessoas humanizadas, que possam se respeitar e serem respeitadas.

Rogers escreve:

A abordagem educacional que descrevemos aqui é uma tentativa de encontrar um método que possa alcançar a meta que designamos de democrática. Uma vez que nossa cultura é, em grande medida, organizada sobre uma base autoritária e hierárquica, e apenas parcialmente sobre uma base democrática, pode parecer para alguns que a educação deva refletir essa ambivalência (ROGERS, 1992, p. 444).

A aprendizagem centrada no aluno e na aluna está em consonância com sociedades democráticas no seu sentido mais genuíno, onde todas as pessoas possam assim se sentir livres para serem pessoas humanas em condições de viver de forma plena o seu crescimento e realização.

\section{Metodologia}

A pesquisa que dá origem ao artigo é de abordagem qualitativa, descritiva e analítica quanto aos seus objetivos, sendo de campo teórico, e o procedimento usado é o estudo bibliográfico e documental. ${ }^{2}$

Sobre a abordagem qualitativa Menga Lüdke e Marli André (2013) afirmam:

A pesquisa qualitativa, segundo Bogdan e Biklen (1982), envolve a obtenção de dados descritivos, obtidos no contato direto do pesquisador com a situação estudada, enfatiza mais o processo do que o produto e se preocupa em retratar a perspectiva dos participantes (LUDKE; ANDRÉ, 2013, p. 14).

2 As abordagens e os instrumentos metodológicos utilizados obedeceram aos procedimentos éticos estabelecidos para a pesquisa científica em Ciências Humanas. Os sujeitos concordaram em participar da pesquisa e assinaram o Termo de Consentimento Livre e Esclarecido; foi oferecida assistência no caso de necessidade emocional ou jurídica; foram apresentados os benefícios e contribuições que os dados podem oferecer ao campo da Educação e do ensino; foi dada garantia de resguardo de informações sigilosas e anonimato, no caso de negação de indicação referencial; houve comprometimento em publicizar as informações coletadas e analisadas. 
Na pesquisa em Educação, não há separação entre o pesquisador ou a pesquisadora e o objeto de estudo, na medida em que a subjetividade é considerada e valorizada. Portanto, a pesquisa de abordagem qualitativa é a que melhor se adequa às problemáticas advindas da realidade do campo educacional e, ainda que recortes quantitativos possam se justificar em algum caso, este não prescinde de análise qualitativa.

Todo ato de pesquisa é um ato de posicionamento político, bem como, de aproximação entre a motivação do pesquisador ou da pesquisadora e a realidade observada, sendo impossível a neutralidade, bem como, o total afastamento do que é familiar. E, ainda, a pesquisa envolve produção de conhecimento e deve ser tratada com toda a sua complexidade e potencialidade. Trata-se de um trabalho que requer muito estudo, planejamento e organização. A incerteza e a inquietação do pesquisador ou da pesquisadora geram questionamento sem resposta evidente. Esse é o ponto que origina uma investigação científica. O caminho escolhido pelo pesquisador ou pela pesquisadora para obter respostas ao seu questionamento consiste na metodologia de pesquisa utilizada, que inclui métodos, técnicas e toda a atuação do pesquisador ou da pesquisadora (TEIXEIRA, 2015, p. 16).

Assumindo-se que não há neutralidade científica, sempre o pesquisador ou a pesquisadora se coloca em um lado da realidade e a assume sob determinada perspectiva, bem como, seu compromisso e responsabilidade ética para com os efeitos físicos, sociais e pessoais. A pesquisa de campo teórico e o procedimento bibliográfico-documental são utilizados tomando como base materiais já elaborados, constituídos principalmente de livros e artigos científicos, nem sempre organizados e sistematizados.

A metodologia se valeu, em primeira etapa, da técnica de pesquisa de levantamento, revisão e análise documental-bibliográfica a partir dos livros de Rogers, de Teses e Dissertações e de artigos já publicados constantes no site do IBICT (Instituto Brasileiro de Informação em Ciência e Tecnologia), na BDTD (Biblioteca Digital de Teses e Dissertações) e no site do banco de dados Scielo. Foi feito um levantamento de produções acadêmicas usando-se determinadas conjugações de palavras-chave (Educação Centrada no Aluno; Abordagem Centrada na Pessoa e Escola; Educação Centrada no aluno; Abordagem Centrada na Pessoa e Educação; Carl Rogers e Educação).

Foram encontradas oito produções em nível de Mestrado e Doutorado, sendo duas na área de concentração de Educação em Ciências: Química da vida e saúde (KONOPKA, 2015; PEREIRA, 2013); três na área de Psicologia da Educação (PEREIRA, 2009; GASPAR, 2009; DUARTE, 1988); duas na área da Educação (GOMES, 2002; COSTA, 1980) e uma na área de Educação, Arte, História e Cultura.

Os artigos encontrados foram poucos e todos eles dentro da área da Saúde, sendo dois oriundos de programas em faculdades de Medicina (de DEUS et al., 2014; ARAÚJO, VIEIRA, 2013) e um da Enfermagem (PETENGILL et al., 2003).

Os dados obtidos no levantamento e na revisão bibliográfica se mostraram positivos e otimistas como respostas à investigação principal. Apesar de não terem sido tão expressivos em quantidade, foram bastante significativos nos resultados chegados, representando uma amostra do frescor das ideias de Rogers para a Educação.

$\mathrm{Na}$ segunda etapa, os dados foram construídos baseando-se no estudo realizado por Rogers e apresentado nas duas primeiras partes do livro "Liberdade para Aprender" (1978), 
em que o autor analisa três experiências de aprendizagens significativas, três experiências de aprendizagem centrada no aluno (que não são o foco de estudo deste artigo). Em síntese, tais experiências aconteceram em níveis diferentes de ensino, sendo a primeira a de uma professora com uma classe de $6^{\circ}$. ano em que trabalha com várias disciplinas. A segunda experiência é de um professor universitário, num curso de Introdução à Psicologia, que é disciplina obrigatória para alunos de pedagogia e facultativa a alunos de outras áreas. Nessa turma relatada na experiência, $25 \%$ dos alunos eram da Pedagogia e os demais a cursavam como eletiva. A terceira experiência é do próprio Rogers num programa de doutorado denominado Liderança Educacional e Comportamento Humano. Ele ofereceu nesse programa o curso "Os valores no Comportamento Humano". São experiências que corresponderiam, no nosso sistema, ao Ensino Fundamental, ao Ensino Superior (Graduação) e à Pós-Graduação.

Os dados construídos e abordados neste artigo advêm da apresentação e análise de cinco experiências atuais, tomadas sob a forma de relatos narrativos escritos, constituindo-se em documentos, provenientes de quatro professoras e um professor, atuantes em diferentes níveis de ensino, no Estado de São Paulo. Os sujeitos que constituem a amostra foram buscados a partir de contatos pessoais e abordados pessoal ou virtualmente, e todos concordaram em participar fornecendo narrativas por escrito, que foram enviadas de volta dentro do prazo estipulado. Elas foram lidas e sistematizadas tematicamente e cotejadas com os princípios rogerianos, a fim de encontrar semelhanças e pontos convergentes à sua proposta educacional e são apresentadas a seguir:

\section{$1^{\circ}$. Relato de EXPERIÊNCIA: Aulas de ReCUPERAÇÃo InTENSIVA - $3^{\circ}$. Ano Ensino Fundamental (Duração: não indicada) - Profa. Ro}

Este é o relato de uma experiência com alfabetização de crianças de $3^{\circ}$. ano do ensino fundamental, de uma professora auxiliar, em uma escola da rede pública na periferia de Campinas (SP), no período de maio a dezembro de 2014, com o objetivo principal de recuperação intensiva definido como um mecanismo de "recuperação pedagógica centrada na promoção da aprendizagem do aluno".

Essa professora tem se mostrado insatisfeita com o modelo tradicional de educação vigente nas escolas por onde trabalha, e ela busca novas formas de lidar com o processo da aprendizagem a partir dos conhecimentos que tem na área em níveis de mestrado e doutorado. Ela é uma estudiosa do assunto com conhecimentos em educação humanista de Paulo Freire, Carl Rogers e outros.

Na referida experiência, ela dispunha de 10 horas/aula semanais distribuídas em dois dias para trabalhar um programa de recuperação com os alunos e as alunas. $\mathrm{O}$ grupo se constituiu de 10 crianças, entre meninas e meninos, com acentuadas dificuldades em ler e escrever.

Com algumas desistências e algumas mudanças feitas pela escola, o grupo se reduziu a cinco crianças. Mas um pouco antes dessa redução acontecer, a professora conta uma experiência que teria redefinido todo o trabalho. Enquanto faziam uma atividade, com dificuldades, uma menina começa a dizer em voz alta que o pai matou um velhinho e por isso teria voltado à prisão e que, por isso, ela não conseguia se concentrar para fazer a atividade. As 
demais crianças pararam as atividades e voltaram a atenção para ela, que agora mostrava sinais de agressão no corpo, deixados pelo padrasto que tentou matá-la.

Mobilizados, os colegas e as colegas passaram a compartilhar suas experiências relacionadas ao crime e à prisão de seus familiares. Um deles contou que o pai fora assassinado antes mesmo de ele nascer. A professora possibilitou que todos e todas interagissem, inclusive ela, alterando, momentaneamente, a dinâmica da aula. Na sua percepção, ali abriu-se uma nova perspectiva de trabalho, visto que as relações, a partir de então, se humanizaram e acabaram os sérios problemas de indisciplina. Ainda que a aluna desencadeadora desse processo tenha se transferido, por questões alheias ao fato, o desenrolar das aulas se manteve nesse novo padrão.

Depois de algumas tentativas para encontrar um caminho adequado para trabalhar com o grupo, a professora escolheu um projeto denominado "Bichodário", com o qual as crianças muito se identificaram e passaram a trabalhar com entusiasmo mediadas pelo laboratório de informática que havia na escola. Para ela, isso redefiniu as aulas de maneira significativa, pois ali surgia uma estratégia de trabalho que se mostrava criativa.

A professora utilizou o método das palavras geradoras de Paulo Freire que, ao valorizar a experiência de mundo do aprendiz, dá outro sentido ao processo. As crianças deixam de ser meros repositórios de conteúdo e passam a criar seus próprios significados. A professora concluiu que, além da técnica utilizada, a aprendizagem desse grupo teria sido facilitada pela liberdade para aprender de que fala Carl Rogers, uma vez que considera que a dor daquela menina e de seus colegas e suas colegas estivesse bloqueando a tendência ao aprendizado deles e ao lhes assegurar liberdade para se colocarem acolhendo-os com autenticidade, aceitação e compreensão empática, puderam se desbloquear e se abrir para o desenvolvimento e crescimento.

\section{$2^{\circ}$. Relato de experiência: Classes de $1^{\circ}$. ano de Ensino Médio (DURA- Ção: Não INDiCAda) - Profa. Br}

Este é o relato de experiência de uma professora de Química, de Ensino Médio, do ano de 2017. Ela relata que assumiu duas salas de primeiro ano de uma escola particular com aproximadamente 40 alunos cada uma, no meio do primeiro semestre. Que uma das salas conversa muito, gerando indisciplina, o que a leva a dar muitas broncas. A outra sala a respeita mais, conversa menos, criando poucos problemas.

Ela relata que em maio os professores foram avaliados pelos alunos e pelas alunas por meio de um instrumento disponibilizado pela escola e que ela não foi bem avaliada. Em agosto, ela recebeu o resultado dessa avaliação por e-mail e ponderou que poderia estar refletindo o fato de ter começado o trabalho no meio do semestre. Em setembro, num dia de aula, na hora do intervalo, recebeu o feedback com os comentários dos alunos e das alunas daquela sala onde tinha mais dificuldades de trabalhar. E os comentários, entre outros, afirmavam que ela não dominava a classe.

A professora conta que ficou muito nervosa e que a palavra "dominação" ficou em evidência em seus pensamentos. Não fazia sentido a ela os alunos e as alunas pedirem que ela dominasse a classe, sendo que eles e elas eram os responsáveis pelas conversas em ex- 
cesso. Portanto, na sala dos professores começou a escrever em seu celular o que gostaria de falar, caso se sentisse encorajada, uma vez que iria dar aulas justamente naquela sala após o intervalo.

Ao entrar na sala de aula, os alunos e as alunas estavam bastante agitados, e ela iniciou pedindo silêncio e atenção a uma pergunta que faria: "Qual a primeira coisa que vem à cabeça de vocês quando escutam a palavra dominação?"

Os alunos e as alunas, inicialmente, acharam a atitude um tanto estranha, mas logo começaram a falar as seguintes palavras: jaula, sexo, correção, animal, zoológico, machismo, selvagem, sadomasoquismo, Hitler, aula, ditadura, líder, rede social, algemas, faca, chicote, homossexualismo, repressão.

$\mathrm{Na}$ sequência, ela circulou as palavras e disse: "Vocês querem mesmo ser dominados?" E, então, a sala ficou em silêncio por alguns segundos. Logo em seguida, ela disse palavras que compunham as ideias a seguir: "Eu não acredito em uma educação vertical onde eu ensino e vocês aprendem, eu também aprendo muito com vocês". "Eu encaro a bronca como se fosse uma discussão, e eu não consigo conversar com quem eu 'discuto' logo depois do ocorrido como se estivesse tudo bem, vocês conseguem? Pois é o que eu tenho que fazer, dar aula normalmente logo após chamar a atenção de vocês." "Após a nossa discussão, não temos tempo para pedir 'desculpas', ficamos separados por uma semana e esse é o tempo que fico chateada quando a nossa aula tem que ser interrompida por discussões." "Sei que ainda posso vir a dar bronca em vocês, porém espero que de alguma forma vocês possam refletir sobre isso que falei." "Estou aliviada em falar isso para vocês, assim como fico aliviada quando consigo me acertar com quem acabei de brigar."

Logo após, passou ao conteúdo previsto para aquela aula e a classe ficou pensativa pelos próximos minutos, mantendo silêncio até o final da aula.

No restante do semestre, observou que os alunos e as alunas ficaram mais próximos dela e até mesmo mais participativos e participativas. Uma aluna até a procurou para compartilhar um problema pessoal.

\section{$3^{\circ}$. Relato de experiência: Classes de $1^{0}$. ANO de Ensino Médio (dura- Ção: NÃo INDICADA) - Profa. LU}

Este relato é proveniente de uma professora de matemática no Ensino Médio de uma escola particular em duas turmas de $1^{\circ}$. ano com 25 alunos em cada uma delas, aproximadamente.

Ela conta que, no segundo semestre de 2017, preparando uma aula de Progressão Aritmética, depois de já ter apresentado o conceito e a primeira parte da teoria, chegou um momento em que precisava falar de Interpolação de Termos Aritméticos. O tópico "Interpolação" era apresentado, no livro didático, como uma aplicação da fórmula de Progressão Aritmética, porém, mesmo sendo classificada como uma aplicação, no momento em que estava preparando a aula percebeu que talvez não fizesse tanto sentido. A aplicação ali era simplesmente substituir valores, sem contextualização alguma e sem relação estabelecida com o "mundo real", como os alunos e as alunas costumam dizer quando se referem ao mundo fora da escola, fora dos livros didáticos, enfim, o mundo em que se vive. Apesar de ter pensado nisso, continuou o preparo da aula, deixando a aplicação para um exercício. 
No dia da aula, seguindo o livro, apresentou o exercício de Interpolação e fez a sua resolução na lousa. De fato, interpolar termos aritméticos fica mais fácil usando a teoria da progressão aritmética, mas por que interpolaria termos aritméticos, no "mundo real"? A pergunta voltava à sua cabeça e, pelo visto, não só na dela, pois terminado o exercício, um aluno perguntou: "Professora, eu entendi como faz, mas eu não entendi o porquê. Quando eu vou precisar interpolar valores, na minha vida?" E ela respondeu: - "Matheus, eu também não sei. A gente pode tentar achar um exemplo agora, uma vez que todos já sabem o que é e como funciona. Será que conseguimos?"

Ele pensava, alguns alunos e alunas ajudavam, outros e outras só conversavam. Para a sua tranquilidade, no momento em que começaram a pensar juntos e ela se acalmou, conseguiu imaginar uma situação em que aquilo faria sentido e apresentou a eles e a elas: "Vamos supor que eu tenha oito outdoors para serem colocados em uma rodovia, entre o $\mathrm{km} 137 \mathrm{e}$ o $\mathrm{km} \mathrm{256,} \mathrm{e} \mathrm{eu} \mathrm{quero} \mathrm{que} \mathrm{eles} \mathrm{estejam} \mathrm{igualmente} \mathrm{espaçados.} \mathrm{Eu} \mathrm{posso,} \mathrm{para} \mathrm{resolver} \mathrm{isso,}$ chamar o km 137 de primeiro termo da progressão, os oito outdoors serão interpolados, e o $\mathrm{km} 256$ é o décimo termo da progressão. Resolvendo isso, consigo achar em qual km deve estar cada outdoor".

Eles e elas se deram por satisfeitos e satisfeitas, mas a professora continuava a achar que ainda poderia haver um exemplo mais próximo da realidade deles e delas.

Terminada aquela aula, era a vez da outra sala e daria o mesmo conteúdo. Como ninguém perguntou, ela resolveu dividir aquela experiência com eles e com elas.

Fez todo o detalhamento da situação, do mesmo jeito que já havia feito na outra sala e então perguntou se alguém teria outra ideia.

Enquanto alguns e algumas pensavam e outros e outras conversavam, uma aluna, muito tímida a chamou até a sua carteira e disse em tom baixo: "Professora, eu pensei em uma coisa, não sei se está certo. A gente pode pensar que tem um remédio para tomar, três vezes ao dia, entre dois horários específicos. Acho que fica um caso parecido com o outdoor e pode resolver com Interpolação".

Ela respondeu: "Genial! Um exemplo extremamente simples e muito mais próximo do cotidiano". Com a devida autorização, da aluna a professora contou à classe e desenvolveu o exemplo na lousa, valorizando a aluna e possibilitando que todos e todas vissem mais sentido no conteúdo. Posteriormente, compartilhou o exemplo com a outra sala também.

$\mathrm{O}$ assunto foi pauta da avaliação e a maioria dos alunos acertou. A professora diz: "Acredito que, a partir do momento em que o conteúdo, até então abstrato, 'conversou' com uma situação tão próxima do cotidiano deles e delas, a aprendizagem se tornou significativa, eles e elas puderam, de fato, compreender e conseguiram aplicar aquela fórmula".

Ao passar por situação como essa, a professora avalia que, mesmo durante a graduação em Matemática, os conteúdos estudados não eram contextualizados. Lembra-se de uma aula de exercícios, em que perguntou ao monitor (ele era responsável por dar as aulas de exercícios) para que servia o Sistema Homogêneo e aquela solução que ela estava tentando entender, mas ele riu e disse que também não sabia. Recorda, ainda, que nas aulas teóricas não sentia liberdade para fazer esse tipo de pergunta ao professor ou professora. Além disso, também sempre lhe vem à mente o quanto a formação em matemática sequer tratava de conteúdos matemáticos estudados no Ensino Médio. A discussão sobre esses conteúdos ou 
o currículo do Ensino Médio acontecia somente nas disciplinas pedagógicas que, na Universidade onde cursou, eram oferecidas na Faculdade de Educação, mas não de maneira a passar por todos os conteúdos que, quando atua como professora, têm que ser trabalhados.

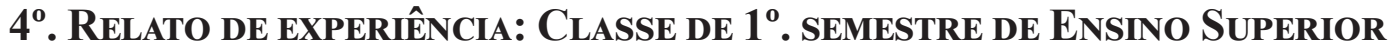 (DURaÇÃo: Não INDiCAda) - Prof. Cl}

Este relato parte de uma experiência de um professor universitário num curso de psicologia na disciplina Bases Filosóficas da Psicologia.

Entre os objetivos da disciplina está o de "desenvolver a consciência crítica", que será aqui considerado nesta experiência. Buscando tornar a disciplina mais interessante aos alunos e às alunas, e considerando esse objetivo, o professor propôs o primeiro trabalho bimestral a partir da roda de apresentações no primeiro dia de aula. Sugeriu que fizessem uma grande roda e disse que gostaria de conhecê-los e de conhecê-las, mas que ninguém estaria obrigado a se apresentar. Sugeriu que pudessem dizer o nome, de que cidade vinham, e o que lhes tinha feito pensar em cursar Psicologia, por que teriam escolhido aquele curso. Disse que poderiam dizer isso e o que mais desejassem ou achassem interessante ou importante dizer, o que quer que fosse, ou mesmo, dizer coisas diferentes do que havia sido sugerido ou ainda, não se apresentar.

Logo um aluno se apresentou, outro (outra) também e o professor também se apresentou. Surgiram muitas informações interessantes. E na medida em que alguém falava de si, de sua história de vida, outro ou outra se via nela e emendava, às vezes pela origem, às vezes pelo problema trazido, às vezes pelo desejo manifesto quanto a ser psicólogo. Ele lista alguns exemplos que foram compartilhados pelos alunos e alunas: "vim do nordeste e estranhei muito quando cheguei aqui, tudo era muito diferente e as pessoas riam da gente"; "vim de Minas, e é muito diferente lá, nunca tinha ouvido falar calçada, lá era passeio"; "frequentei psicólogo quando era criança por bastante tempo, minha mãe era depressiva e a terapia me ajudou muito"; "eu também, porque eu era hiperativa e tomava remédio e ia na psicóloga, fui bastante tempo até deixar de tomar remédio"; "eu também tinha transtorno de déficit de atenção e frequentei uma psicóloga bastante tempo"; "eu era seminarista e lá conversávamos com psicólogo toda semana, sempre se discutia se era mesmo isso que queria ser"; "ah... sempre gostei de ajudar as pessoas e acho que a psicologia vai me ajudar nisso"; "eu sou artista, artesão, e viajei o país todo trabalhando e fui conhecendo outros artesãos, é uma vida muito diferente de quem nunca saiu de casa"; "o que me marcou muito foi uma professora de psicologia, tudo que ela falou sobre o assunto me fez querer ser psicóloga também"; sou pastora e acho que a psicologia vai me ajudar no trabalho, na minha igreja é tradição os pastores fazerem psicologia"; "sempre fiz trabalho voluntário e acho que isso tem a ver com psicologia"; "gostaria de entender a mente das pessoas".

Nessa turma, havia cerca de 70 alunos e nas duas semanas seguintes ela teria mais de 80 pessoas e seria dividida em duas turmas. Mas, nessa primeira aula, ao final de todos e todas os que desejavam se apresentarem, eles e elas foram convidados e convidadas a pensar um pouco sobre tudo que tinham falado deles e delas mesmos, dos mais diferentes assuntos que apareceram ali. Surgiram comentários rápidos, com expressões de surpresa 
sobre o que acabavam de ouvir. E então o professor falou a respeito do trabalho bimestral e lhes perguntou o que achavam de trabalhar sobre temas relacionados aos que ali surgiram. De novo fizeram cara de surpresa, de "como assim?" O professor foi à lousa e os convidou a levantar, com ele, alguns temas que poderiam estar presentes nas falas deles e que poderiam ser interessantes estudar. Foram surgindo, com a ajuda do professor, aqui e ali, vários temas que foram sendo listados. Então lhes pediu que, naquela semana, formassem os grupos por interesse de tema e buscassem um artigo acadêmico ou um documentário que tratasse do assunto.

Alguns e algumas não tinham tido ainda contato com um artigo científico e outros e outras não sabiam o que era um documentário, sobre o que conversaram, então, com o professor. Deveriam enviar ao professor, por e-mail, os membros do grupo, o tema, e o artigo ou documentário que encontrassem. Foram e voltaram muitos e-mails até serem definidos os artigos e documentários relacionados ao tema escolhido pelo grupo.

Alguns e algumas não gostaram e sentiram dificuldade em escolher tudo isso e pediam ajuda e orientação, o que foi feito. Mas a maioria aprovou e se disse surpresa, não imaginando que alguém tivesse escrito sobre algo que ele ou ela tinha vivido.

Ao longo do bimestre foram feitos trabalhos em grupos e apresentados à sala, bem como, entregue uma versão por escrito. Havia liberdade de escolha para formação dos grupos e para o tema, podendo inclusive mais de um grupo escolher o mesmo tema. Alguns e algumas fizeram isso e outros e outras preferiram mudar o tema quando sabiam que outro grupo também escolhera o mesmo tema. E o critério para decidir quem ficava com o tema era definido entre os grupos envolvidos.

Na preparação dos trabalhos, apresentação em sala e discussão houve uma ampliação dos assuntos levantados, percepção de muitos outros a eles relacionados e qual a relação que tudo isso poderia ter com o querer ser psicólogo, bem como, as muitas maneiras de exercer essa profissão. Questões ideológicas, sociais, econômicas, políticas, religiosas, emocionais e outras emergiram e deixaram abertas as possibilidades para nelas pensar e refletir. Considerou o professor que a temática e esse jeito tenham estado mais próximos dos interesses dos alunos e das alunas e por isso facilitado a aprendizagem e favorecido atingir o objetivo de desenvolver uma maior consciência crítica a partir de questões por eles vivenciadas.

\section{$5^{\circ}$. Relato de experiênCia: Disciplina em CURSo de Pós-graduaÇÃo (Mestrado) (DURaÇÃo: Não indiCAda) - Profa. Re}

Este é o relato de uma experiência, no ano de 2012, de uma professora no curso de Mestrado em Educação numa disciplina totalmente nova para ela, "Epistemologia e Educação", que afirma ter assumido como um desafio no que toca às discussões teóricas, bem como, no fazer docente em termos da prática em aula.

Ela busca construir um percurso com conteúdos e textos que possam responder à ementa da disciplina e o apresenta aos alunos e às alunas. Essa proposta poderá ser refeita e redirecionada, a partir das contribuições dos alunos e das alunas. Acredita que o foco não é ensinar, mas, a partir de proposições, de desafios, de questões, pensar. Logo, por 
uma curiosidade e interesse despertados pelas leituras, tentar provocar possibilidades de aprendizado coletivo. Sendo assim, "cada aula não tem como ser desenhada a caneta, mas rascunhada a lápis".

O objetivo inicial era amplo, mais um propósito do que um lugar definido a chegar: Pensar a Educação por meio de bases epistemológicas oriundas da filosofia da Educação visando refletir sobre: o que é o conhecimento? Como obtemos conhecimento? Como defender e argumentar sobre os modos de conhecimento e interpretação válidos, mas nem sempre suficientes e duradouros?

A primeira parte da aula era mais teórica, ancorada em leitura, conversa e discussão da bibliografia indicada. Nesse momento, a ideia é que os conceitos e argumentos dos autores e autoras servissem para ajudar a pensar sobre a realidade da vida, da pesquisa, do ser/fazer professor ou professora, do ser/fazer pesquisador ou pesquisadora, e então, ir percebendo como as leituras ecoam e repercutem em cada um e em cada uma, ou seja, o que faz sentir e pensar. Aqui a ideia não era ensinar, mas ver o que era possível fazer pensar e talvez, aprender. Aprender cada um e cada uma o que fosse possível naquele dia, naquele momento, para aquela pessoa e para o grupo na sua multiplicidade. A segunda parte da aula era prática e consistia, a cada encontro, de oficina de escrita de cartas ou diários a respeito do processo de escrita acadêmica e de construção da pesquisa e do fazer-se pesquisador ou pesquisadora, baseando-se numa escrita ensaística, onde mais se pergunta do que se encontra respostas. A escrita é o exercício de visibilidade do movimento do pensamento. Escrevia-se para um suposto e desconhecido leitor ou leitora.

Ao final de cada aula, a professora recolhia as cartas e as levava para casa, quando as lia e tomava contato com os processos internos de cada um e de cada uma. Na aula seguinte, as produções eram trocadas aleatoriamente e cada um ou cada uma lia o conteúdo e conversava por escrito com o texto lido no sentido de alimentar as discussões e o pensamento sobre si e sobre o outro ou outra, promovendo subjetivação.

O percurso durou 15 aulas. Ao final do curso, pediu a cada um e a cada uma, uma narrativa tomando como base a seguinte proposição: Os sujeitos constroem-se nos processos de sua escrita e nesse exercício pensam-se desta ou daquela forma, elaboram, digerem leituras e sensações e sentimentos, entram em dilemas com o pensamento e com a página em branco, deslocam-se, duvidam, silenciam, portanto, passam por processos de subjetivação. A partir das trocas efetuadas ao longo do semestre, reescrever um texto em que estejam presentes as tentativas de se pensar, de se subjetivar como sujeito-pesquisador. Esse exercício foi tomado com uma das formas de avaliação, já que é preciso, institucionalmente, atribuir um conceito a cada aluno e a cada aluna.

A professora relata que a experiência foi interessante e peculiar, especialmente porque todos e todas toparam fazer o percurso assumindo esse modo e, ao longo do percurso, cada um e cada uma foi podendo conhecer mais de si e do outro ou da outra e também, de como é pesquisar algo que toca e atravessa por todos os sentidos.

As narrativas finais foram entregues à professora e compartilhadas entre os alunos e as alunas como uma forma de avaliar os aprendizados havidos. A professora afirma que apesar de ter um considerável repertório docente, se sente desafiada pelo novo e desconhecido e é assim que vê, para ela, o ser professor ou professora, desde as experiências na educação infantil e no ensino fundamental. 
Tentando avaliar aonde chegaram acredita não haver respostas fechadas para "o que é o conhecimento?", "como obtemos conhecimento?" e "como defender e argumentar sobre os modos de conhecimento e interpretação válidos, mas nem sempre suficientes e duradouros", o que é ótimo, mas refletir a partir de chaves teóricas e práticas e se repensar para procurar fazer e viver de forma alinhada entre pensamento, sentimento, enunciação e ação.

\section{ANÁLISE DE DADOS}

Essas recentes experiências colhidas em anotações e aqui exibidas demonstram a presença das condições facilitadoras em professores e professoras que buscam criar condições favoráveis para a aprendizagem significativa, resultando num sentido não só aos alunos e alunas, como também àqueles e àquelas que não se satisfazem apenas em dar aulas ou acreditar que possam ensinar sem a preocupação de saber se está ocorrendo a aprendizagem.

Os indicadores que apontam para a aprendizagem significativa, a partir dos dados, envolvem: o cognitivo e o sensível articulados e acionados, a motivação inicial e interna da aluna e do aluno, mudanças significativas em termos epistemológicos e afetivos, a autopercepção do aprendido, a experiência como condição fundamental.

Embora não se arrisque afirmar que um conhecimento sobre a proposta educacional de Carl Rogers, na formação desses professores e professoras, poderia favorecer, em muito, essa tendência de facilitadores já neles, e nelas, presente - o que implicaria estabelecer uma relação direta entre o conhecimento de alguma teoria/autor/texto na formação inicial e o processo formativo (como transformação subjetiva) e, ainda, reduzir a complexidade dos processos de formação ao contato com uma proposta educativa -, é possível pensar que pode ser um disparador de curiosidade pela busca de um referencial que ancore princípios epistemológicos e atitudinais autoidentificados previamente ou suscitados pela leitura e estudo do pensamento rogeriano.

Percebe-se, ao aproximarem os relatos, que as experiências se constituem como sendo significativas, tanto para o professor ou professora quanto para os alunos ou alunas, já que podem ser extraídas delas as tais atitudes facilitadoras, que em educação Rogers assim as designa: a) autenticidade; b) apreço, aceitação, confiança e c) compreensão empática.

Por autenticidade, entende-se a postura ou atitude presente no professor ou na professora percebida pelo aluno e pela aluna como uma pessoa real que entra em contato com ele ou ela, e não uma representação de alguém ou de alguma função, como a de "ser professor" ou "ser professora".

Por apreço, aceitação, confiança, entende-se outra postura ou atitude presente no professor ou na professora percebida pelo aluno e pela aluna como alguém que o e a aceita inteiramente com seus temores, hesitações e alegrias. Sentem-se estimado e estimada, considerado e considerada positivamente por ele ou ela, podendo lhes confiar suas dúvidas, mesmo as de cunho pessoal.

Por compreensão empática, entende-se uma atitude presente no professor e na professora e que pode ser percebida pelo aluno e pela aluna como alguém que tem a habilidade de compreendê-lo e compreendê-la em suas reações íntimas, alguém que pode perceber o modo como ele e ela veem o processo de aprendizagem significativa. 
Rogers se torna professor universitário e exerce esse trabalho por vários anos concomitantemente ao de psicoterapeuta. Como professor, conhecia as dificuldades dos alunos e das alunas em aprender, a apatia, o desinteresse. Conhecia também as estruturas educacionais, seu funcionamento, sua hierarquia, seus currículos, previamente estabelecidos. O sistema era autoritário, rígido, hierarquizado, centrado na autoridade dos administradores e administradoras, dos professores e professoras e do currículo. Não satisfeito com suas aulas e com os resultados delas, Rogers não demorou em começar a questionar aquele contexto e uma frase dele sobre isso sintetiza bem o seu questionamento: "Se confiava em meus clientes, por que não confiava em meus alunos?” (ROGERS, 1977, p. 202).

Convencido dos resultados de sua prática psicoterápica, já então bastante pesquisada e divulgada por ele e por uma equipe que com ele trabalhava, sendo já conhecidos os conceitos básicos dessa teoria nascente, ele não demorou em considerar se as mesmas condições facilitadoras poderiam também favorecer o processo de aprendizagem.

Analogamente ao processo de psicoterapia, deve o professor ou a professora criar um clima acolhedor e facilitador à aprendizagem.

Estabelecidas essas condições, Rogers acredita que a aprendizagem significativa se dá em todos os níveis de educação e de idade dos alunos e das alunas.

\section{CONSIDERAÇões FINAIS}

O artigo visou apresentar e analisar os conceitos e o pensamento de Carl Rogers de maneira a trazer as suas contribuições no campo da Educação para o contexto atual.

Considera-se que os dados exibidos e analisados possam trazer uma contribuição para a área da Educação, na medida em que podem ampliar a presença de Carl Rogers nas questões educacionais. As discussões e os debates atuais pouco o incluem e, para muitos e muitas, ele nem é conhecido no meio.

A partir desta pesquisa bibliográfica são necessárias futuras pesquisas de campo empírico com entrevistas feitas junto a alunos e alunas, egressos e egressas de escolas que tenham foco maior nos alunos e nas alunas, sobretudo aquelas de inspiração construtivista e escolanovista ou humanistas, de inspiração rogeriana, ou não.

Tais pesquisas estariam, também elas, como queria Rogers, centradas nas pessoas que vivenciaram uma educação centrada no aluno ou na aluna e poderiam oferecer dados dessa experiência em relação à continuidade de seus estudos, se teria sido facilitadora ou dificultadora na continuidade da vida estudantil ou acadêmica. Poderia, também, saber de tais pessoas, o impacto dessa experiência na vida, se teria sido significativo ou não, em que sentido.

Ainda que técnicas diferentes possam estar sendo aplicadas em algumas instituições, algumas denominadas de metodologias ativas, consideradas como "centradas no aluno" se elas não contarem com as atitudes facilitadoras do professor ou da professora que acredita que o aluno e a aluna são dignos de confiança e devem participar ativamente do processo como um todo, mas somente na execução, efetivamente não estará ocorrendo uma mudança de paradigma e o processo continuará centrado no professor ou na professora, uma vez que é ele ou ela quem prepara, aplica, controla e avalia o resultado da "metodologia" aplicada. 
Por fim, tanto o estudo bibliográfico quanto o documental evidenciam a atualidade, a pertinência e a validade do pensamento de Rogers para se refletir e enfrentar as problemáticas educacionais advindas da complexidade do campo e da realidade, nos tempos atuais.

\section{REFERÊNCIAS}

ANDERSON, H. H.; BREWER, H. M. Studies of teacher's classroom personalities: I. Dominative and socially integrative behavior of kindergarten teachers. App. Psychol. Monogr., 1945, no. 6, 157 p.

ARAÚJO, Eliana S. C. de; VIEIRA, Vania M. de O. Práticas docentes na Saúde: contribuições para uma reflexão a partir de Carl Rogers. Psicol. Esc. Educ. v. 17 n. 1, Maringá, jun., 2013.

COSTA, Carlos A. J. A pedagogia libertaria de Carl Rogers: um estudo de suas características. 1980. Dissertação (Mestrado em Educação) - Programa de Pós-graduação em Educação, da Universidade Estadual de Campinas, Campinas, 1980.

de DEUS, José M.; NONATO, Dejan R.; ALVES, Rosane R. F.; SILVA, Marilia M. de M.; AMARAL, Alexandre F.; BOLLELA, Valdes R. Aula centrada no aluno versus aula centrada no professor. Desafios para mudança. Rev. Bras. Educ. Med., v. 38, n. 4 Rio de Janeiro, out./dez., 2014.

DUARTE, Vera L. C. As relações interpessoais em sala de aula num curso de inglês na universidade: o desempenho do aluno numa situação de medo, 1988, 131s. Dissertação (Mestrado em Psicologia) - Programa de Estudos Pós-Graduados em Educação: Psicologia da Educação, da Pontifícia Universidade Católica de São Paulo, São Paulo, 1988.

EISERER, Paul E. The implications of non-directive counseling for classroom teaching. Growing Points in Educational Research, Relatório Oficial. Washington D.C.: Associação Americana de Pesquisas Educacionais, 1949.

GASPAR, Maria A. D. Aprendendo a conviver: um estudo que prioriza as relações interpessoais na comunidade escolar, 2009, 216s. Tese (Doutorado em Educação: Psicologia da Educação) - Programa de Estudos Pós-Graduados em Educação: Psicologia da Educação, da Pontifícia Universidade Católica de São Paulo, São Paulo, 2009.

GOMES, Regina C. N. Formação Humanista do Médico: contribuições para uma reflexão na concepção de Carl Rogers, 2002, 162s. Dissertação. (Mestrado em Educação) - Faculdade de Educação da Universidade Estadual de Campinas, Campinas, 2002.

KONOPKA, Clóvis L. A aprendizagem na concepção humanista de Carl Rogers e sua contribuição para o desenvolvimento das atitudes dos estudantes de graduação em 
medicina da UFSM, 2015, 168s. Tese (Doutorado em Educação e Ciências) - Programa de Pós-Graduação em Educação em Ciências: Química da Vida e Saúde, da Universidade Federal de Santa Maria, Santa Maria, 2015.

LUDKE, Menga; ANDRÉ, Marli E. D. A. Pesquisa em Educação: Abordagens qualitativas, 2. ed. Rio de Janeiro: EPU/, 2013.

PEREIRA, Ana L. Desvendando os mitos do bom professor: um estudo com professores da educação básica, 2009, 116s. Dissertação (Mestrado em Psicologia), Pontifícia Universidade Católica de São Paulo, São Paulo, 2009.

PEREIRA, Hugo C. P. Educação médica a partir da perspectiva humanística de Carl Rogers: uma vivência de sala de aula, 2013, 171s. Tese (Doutorado em Educação e Ciências) - Programa de Pós-Graduação em Educação em Ciências: Química da Vida e Saúde, da Universidade Federal de Rio Grande, Rio Grande, 2013.

PETTENGILL, Myriam A. M.; NUNES, Cristina B. BARBOSA, Maria A. M. Professor e aluno compartilhando da experiência de ensino-aprendizagem: a disciplina de enfermagem pediátrica da Universidade Federal de Mato Grosso do Sul. Rev. Latino-Am. Enfermagem, Ribeirão Preto, v. 11, n. 4, jul./ago. 2003.

ROGERS, Carl R. Terapia Centrada no Cliente. São Paulo: Martins Fontes, 1992.

. Psicoterapia e Consulta Psicológica. São Paulo: Martins Fontes, 1987.

. Liberdade para Aprender. Belo Horizonte: Interlivros, 1978.

. A Pessoa como Centro. São Paulo: EPU, 1977.

SILVA, Tomaz T. Documentos de Identidade: uma introdução às teorias do currículo, 3 . ed. Belo Horizonte: Autêntica, 2011.

. O currículo como fetiche: a poética e a política do texto curricular. Belo Horizonte: Autêntica, 2010.

TEIXEIRA, Nádia F. Metodologias de pesquisa em educação: possibilidades e adequações. Caderno pedagógico, Lajeado, v. 12, n. 2, p. 7-17, 2015

WITHALL, John. The development of a technique for the measurement of social-emotional climate in classrooms. Tese de Ph.D., Universidade de Chicago, 1948. 


\section{DADOS DOS AUTORES:}

\section{Clóvis Martins Costa}

Mestre em Educação pelo Centro Universitário Salesiano de São Paulo. Docente no Centro Universitário de Jaguariúna/SP-Brasil.clovismcosta@uol.com.br

\section{Renata Sieiro Fernandes}

Pós-doutorado em Educação pela Universidade Estadual de Campinas. Docente do Programa de pós-graduação em Educação do Centro Universitário Salesiano São Paulo/SP- Brasil.rsieirof@hotmail.com

Submetido em: 25-2-2019

Aceito em: 29-7-2020 